\title{
Large bowel mucosal dysplasia and carcinoma in ulcerative colitis
}

\author{
DC ALLEN, JD BIGGART, PC PYPER* \\ From the Histopathology Laboratory and *Surgical Unit, Belfast City Hospital, Belfast
}

SUMMARY The clinicopathological details of eight cases of ulcerative colitis complicated by carcinoma of the colon are described. There was a total of 14 primary colonic cancers, six of which were not detected before pathological examination of the resection specimens. The reason for this may be related to atypical tumour growth patterns. Three occurred in flat mucosa, one in a mucosal plaque lesion, and another in polypoidal mucosa. The occurrence, distribution, and morphology of mucosal dysplasia were noted in both resection specimens and biopsies taken at varying stages before resection. Tumour was associated with normal and adjacent dysplastic mucosa of varying grades. The extent and grade of dysplasia were not reliable indicators of tumour differentiation or subsequent clinical outcome. Only two cancers were poorly differentiated. In five cases a total of 23 mucosal biopsies were taken, all less than 12 months before resection. Three rectal biopsies were graded positive for dysplasia and three colonic biopsies indefinite for dysplasia. The subsequent resection specimens showed both dysplastic and carcinomatous changes. Three rectal and 14 colonic biopsies were graded negative for dysplasia despite positive findings in the subsequent resection specimens. This anomaly is partly attributed to the patchy nature of dysplasia in colitic mucosa. Two cases illustrate the possibility of dysplasia pursuing a rapidly progressive course. The mucosal changes of ulcerative colitis were assessed using a recently introduced and standardised international classification.

It is well recognised that carcinoma of the colon is a complication in patients with longstanding ulcerative colitis. This was initially brought to attention in 1925 by Crohn and Rosenberg, who described a rectal carcinoma arising in a patient who had had ulcerative colitis for 14 years. ${ }^{1}$ The tumour arose on the basis of malignant transformation within a hyperplastic and polypoidal mucosa. The association of ulcerative colitis with carcinomatous change was further corroborated by Bargen in $1928,{ }^{2}$ who reported 17 such cases and noted that "wherever there were islets of regenerating mucosa they were malignant." $\mathrm{He}$ proposed a sequence of events: chronic ulcerative colitis, multiple polyposis, and malignant disease. Over the ensuing years there have been a number of detailed reports establishing both the clinical and mucosal parameters seen in ulcerative colitis undergoing malignant changes. ${ }^{3-18}$

Estimates of the number of patients with ulcerative colitis developing carcinoma vary; a rough figure is $3 \%$ of all those suffering from the dis-

Accepted for publication 19 September 1984 ease. ${ }^{612} 18$ Variations in this figure may be explained partly by differing criteria used for patient group selection in individual reports. ${ }^{19}$ What has emerged is that there are certain risk groups more likely to develop carcinoma. This association has been made with an early age at onset of colitis, ${ }^{6913}$ the duration of colitis, ${ }^{56 ! 318}$ and the extent and severity of colitis. ${ }^{56}$ Malignancy in ulcerative colitis may be seen in patients with either chronic continuous ${ }^{6}$ or intermittently active disease. ${ }^{20}$ The susceptible patient has emerged as one with a chronic disease of pancolic distribution and of $10-20$ years' duration. ${ }^{12}$ The development of carcinoma in ulcerative colitis has been regarded as a sinister complication due, in part, to the hidden clinical expression of tumour growth, masked by symptoms of the colitic process. Thus the resultant carcinomas have presented late and have been considered of poor prognosis. Other features contributory to this pessimistic outlook include multiple primaries, a more even colonic distribution, atypical macroscopic appearances, and a higher proportion of poorly differentiated tumours. ${ }^{10} " 1$ The notion of carcinoma arising in altered colitic mucosa ${ }^{12}$ has grown to an acceptance of precancer- 
ous or dysplastic mucosal changes being associated with and even predating the carcinoma. As early as 1949 Warren and Sommers ${ }^{4}$ proposed a stage of precancerous epithelial hyperplasia. In 1967 Morson and Pang ${ }^{7}$ established the use of rectal biopsy as an aid to the diagnosis of cancer in ulcerative colitis. A natural extension of this has been the surveillance of colitic patients using the colonoscope as a means of both observing and sampling the bowel mucosa. ${ }^{151821}$ The histological interpretation of this material is often difficult, particularly in the field of regenerative epithelial changes versus true dysplasia. A recently introduced and standardised classification of dysplasia in inflammatory bowel disease prepared by an international panel of pathologists should be of help. ${ }^{22}$ This will establish morphological standards by which a more accurate reflection of the incidence and natural course of dysplasia and its importance may be judged.

The purpose of this study was to describe the clinicopathological features of cancer arising in eight patients with ulcerative colitis, five of whom had mucosal biopsies performed before resection. Part of this material forms the basis of another report (p 18).

\section{Material and methods}

In the 20 year period $1963-83$ eight resection specimens have been reported in this laboratory as ulcerative colitis complicated by carcinoma. In five of these cases a total of six rectal and 17 colonic mucosal biopsies, all taken less than 12 months before resection, were available for examination. The resection specimens were opened at the time of removal and all tissues were fixed in $10 \%$ formalin. Tissues were routinely processed, embedded in paraffin, sectioned at $5 \mu \mathrm{m}$, and stained with haematoxylin and eosin. Selected blocks were stained for mucin production with periodic acid Schiff-diastase. The mucosal biopsies were examined through multiple levels. There was an

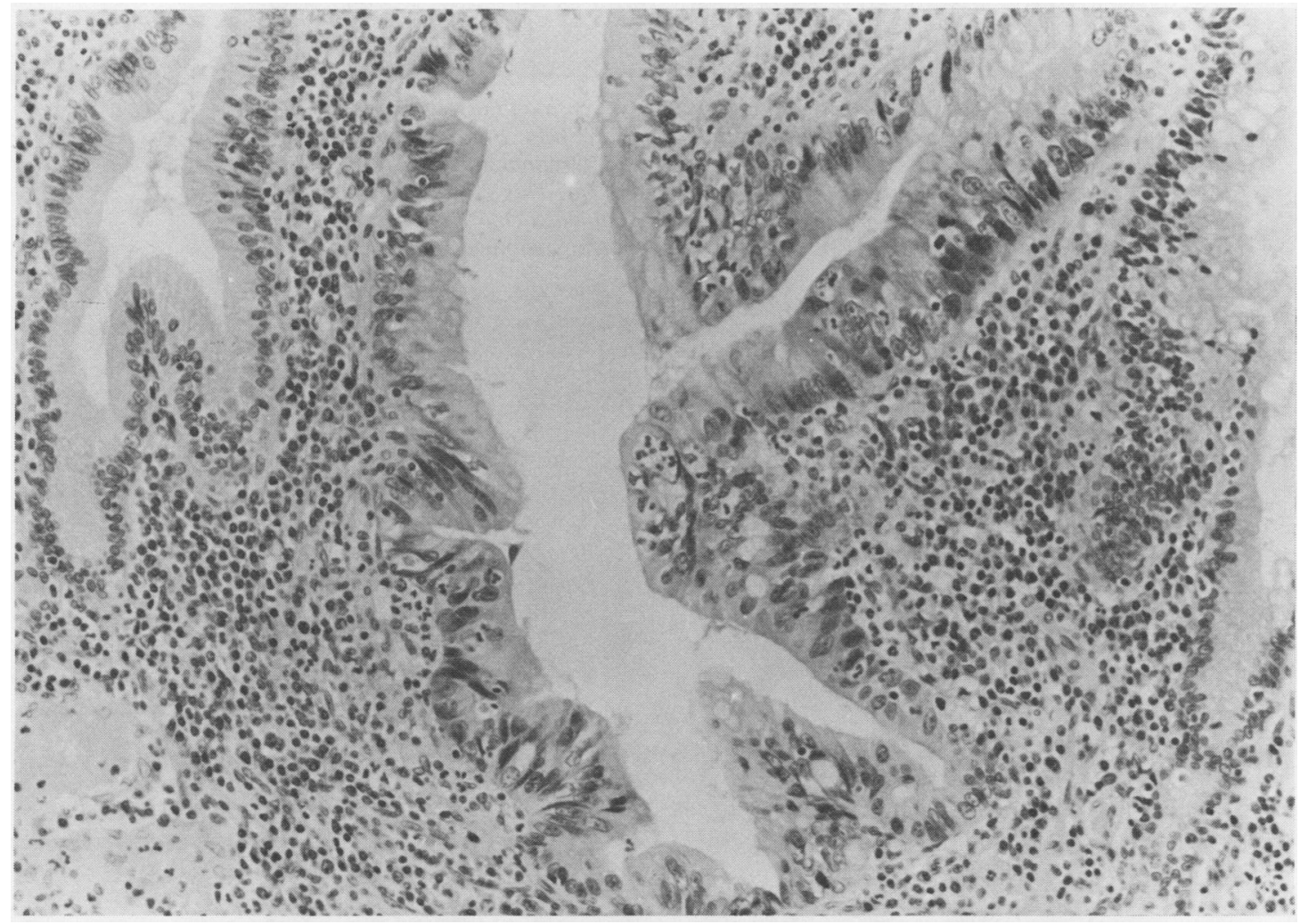

Fig. 1 Two normal gland crypts flanking a gland showing regenerative changes. There is budding of the gland and the epithelium shows nuclear pleomorphism with a tendency to stratification. The nuclei have dispersed chromatin with prominent nucleoli. Intraepithelial polymorphonuclear leucocytes are present. Negative for dysplasia. Haematoxylin and eosin. $\times 240$. 


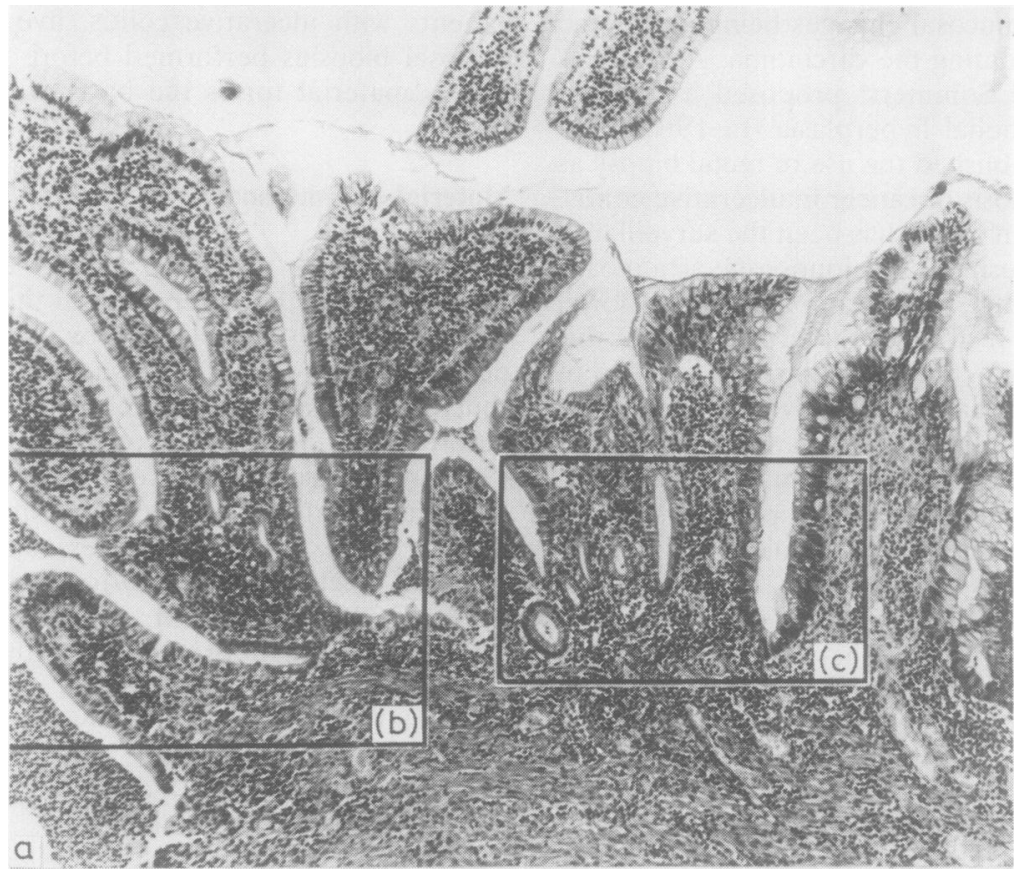

Fig. 2(a) Actively inflamed and regenerative mucosa on the left adjoining mucosa positive for high grade dysplasia on the right of the field. Both show a villous architectural alteration. Haematoxylin and eosin. Original magnification $\times 85$. (b) The area boxed on the left side of the field in (a). This shows part of a crypt abscess (left) with accompanying regenerative epithelial changes. Negative for dysplasia. Haematoxylin and eosin. Original magnification $\times 260$.

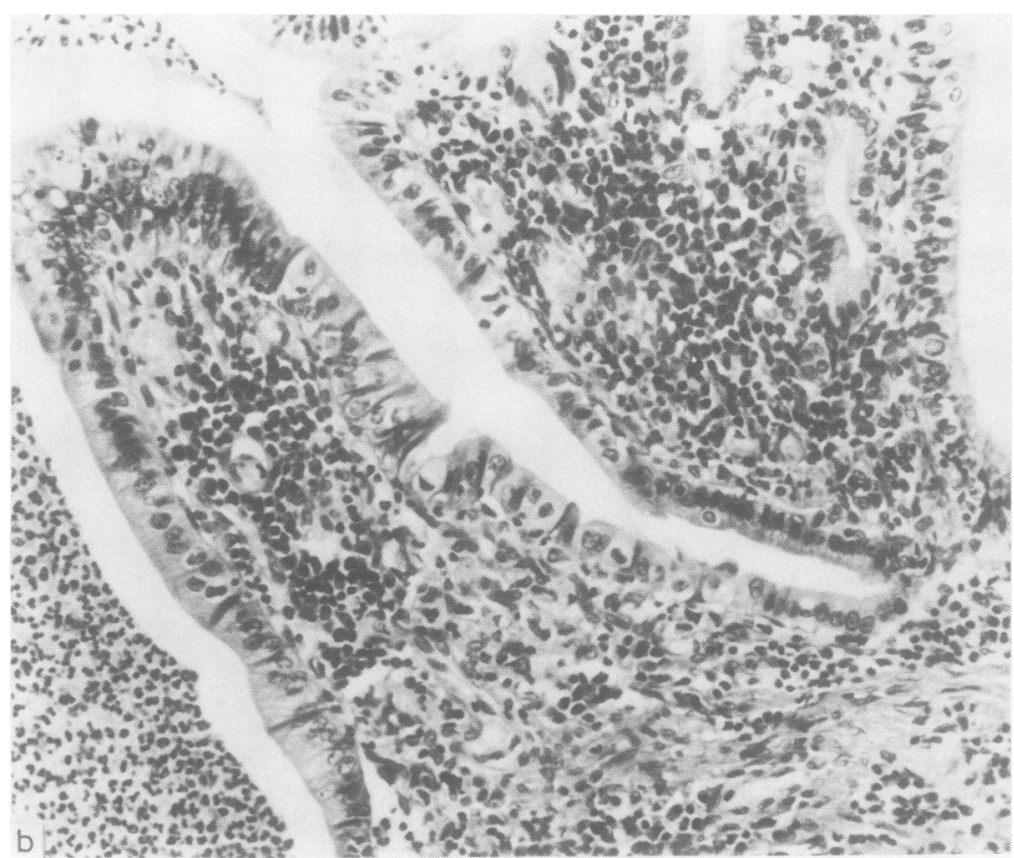




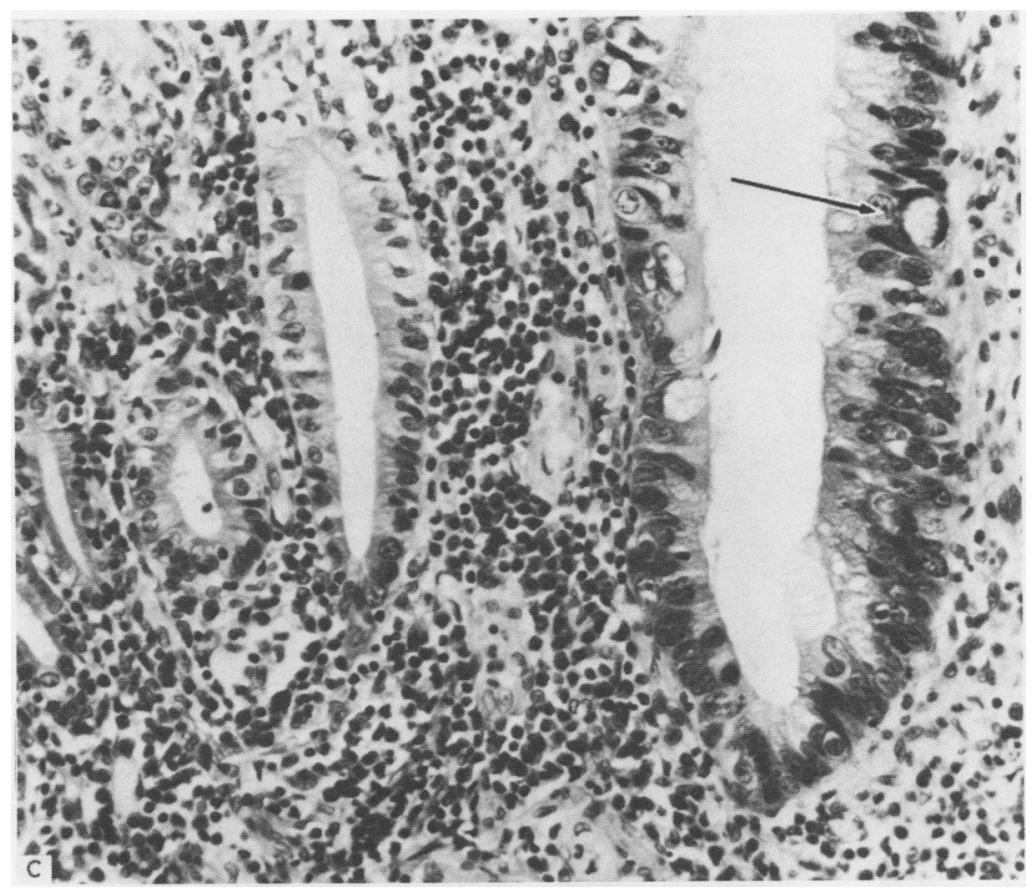

Fig. 2(c) The area boxed on the right of the field in (a). Regenerative and normal epithelium on the left contrasts with high grade dysplasia on the right. There is nuclear pleomorphism, hyperchromatism, and stratification. A dystrophic goblet cell is arrowed. Haematoxylin and eosin. Original magnification $\times 300$.

average of 11 blocks for each resection specimen, giving representation of each carcinoma and its relation to serosal and mesenteric tissues; ascending, transverse, descending colonic, and rectal tissues were also represented. There were additional blocks of lymph nodes in each case. Follow up information was available for periods varying from eight months to 21 years after operation. Three patients died and were examined at necropsy.

The mucosal changes of ulcerative colitis were assessed by two of us (DCA, JDB), using a double headed microscope and by applying a standardised classification.22 Disease activity was classified as either active or inactive (quiescent) inflammation. Dysplasia is defined as an unequivocal neoplastic epithelial alteration, and this is judged by both architectural and cytological disturbances. Mucosa was graded for dysplasia and placed in the following categories: negative, indefinite, or positive for dysplasia. The indefinite category subdivides into probably negative, unknown, and probably positive groups. The positive for dysplasia category splits into low and high grade dysplasia. The following are helpful indicators in assessing dysplasia:

1 Architectural alteration-for example, a villous pattern or excessive crypt budding, with or with- out adenomatous glandular proliferation.

2 Cytological abnormalities-for example, nuclear pleomorphism, nuclear hyperchromatism, loss of nuclear polarity, nuclear crowding, nuclear stratification, and mitoses. In this context the presence of Paneth cells (in the left colon) and, in particular, dystrophic goblet cells are a low power marker which should stimulate a high power search to exclude dysplasia.

3 A knowledge of the range of architectural and cytological abnormalities which may be encountered in repairing regenerative mucosa.

Regenerative mucosa may show sparse glandular budding and epithelial changes such as nuclear enlargement, a tendency for nuclear stratification, and even mitoses (Fig. 1). Judging the epithelium by the company it keeps in terms of inflammatory cells, in particular polymorphs, is reassuring. Useful pointers are polymorphonuclear leucocytes migrating through the epithelium and destructive, inflammatory crypt lesions adjacent to suspicious epithelium. The nuclei in regenerative epithelium are lighter staining with open, scattered chromatin and often prominent basophilic nucleoli. Regenerative mucosa may also show a villous architectural arrangement and therefore assessment of any inflammatory com- 


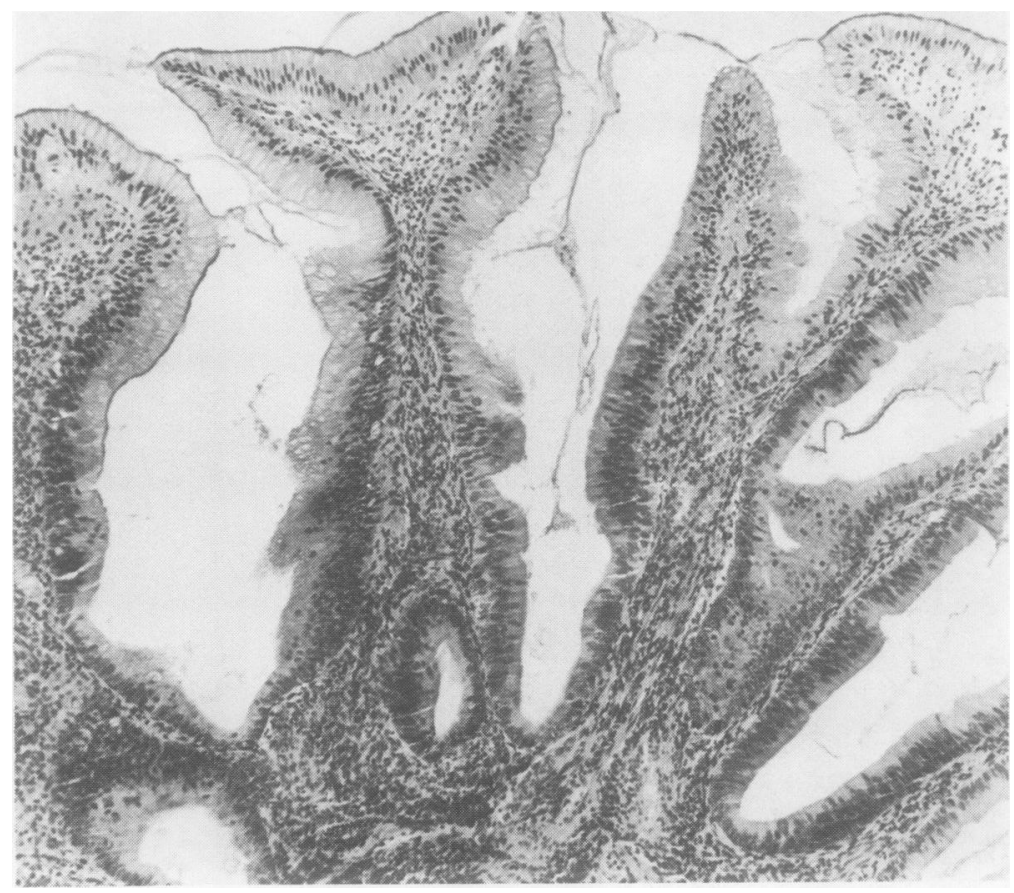

Fig. 3 Mucosal biopsy with a villous architecture, positive for high grade dysplasia in the crypts and half way up the glands. There is crypt to surface epithelial maturation. Haematoxylin and eosin. Original magnification $\times 100$.

ponent and nuclear morphology at high power is necessary (Fig. 2). Dystrophic goblet cells should not be used as a sole criterion for dysplasia as they are encountered in mucosa which is negative, indefinite (Fig. 6b), and positive for dysplasia (Fig. 2c). Mucosa positive for dysplasia will show nuclear hyperchromatism, crowding and stratification, and inflammation will not be a prominent feature. Active inflammation does not, however, exclude a diagnosis of positive dysplasia if the cytological and architectural alterations indicate it (Fig. 2). This is readily apparent in high grade dysplasia, but a diagnosis of low grade dysplasia in the presence of active inflammation should be made with extreme caution. Mucosa positive for dysplasia may show dysplastic crypts with progressive maturation towards the surface epithelium (Fig. 3) or dysplasia affecting the whole gland (Fig. 6c). The grade of dysplasia is dictated by the worst area. Occasionally, dysplasia may be seen in serrated, metaplastic type columnar epithelium or flat, architecturally attenuated mucosa (Fig. 4). Architectural alteration in dysplastic mucosa may take several forms, each of which may serve as a warning at low power. These include a villous growth pattern (Fig. 2), glandular crypt budding beyond that normally seen in simple repair, and glandular proliferation, which may become polypoidal with a configuration and histology indistinguishable from that of a common tubular (adenomatous) polyp of the colon. Mucosa positive for high grade dysplasia includes the term carcinoma in situ, showing a back to back arrangement of dysplastic glands within the confines of the lamina propria. These categories are not separated as they have similar therapeutic implications. ${ }^{22}$

The colonic carcinomas were staged after Dukes and Bussey. ${ }^{23}$

\section{Results}

The clinicopathological features of eight cases of ulcerative colitis complicated by carcinoma are summarised in Table 1. There was an equal sex distribution. All patients had clinical and pathological evidence of total colitis, the inflammation being quiescent in five cases. Inflammation was uniform throughout the large bowel except in case 7, where disease activity was greater in the left colon. The average age at onset of colitis was 31 years with an average disease duration of 16.85 years (range 4-35 years) to the time of diagnosis of carcinoma. Five patients had had colitis for more than 10 years 


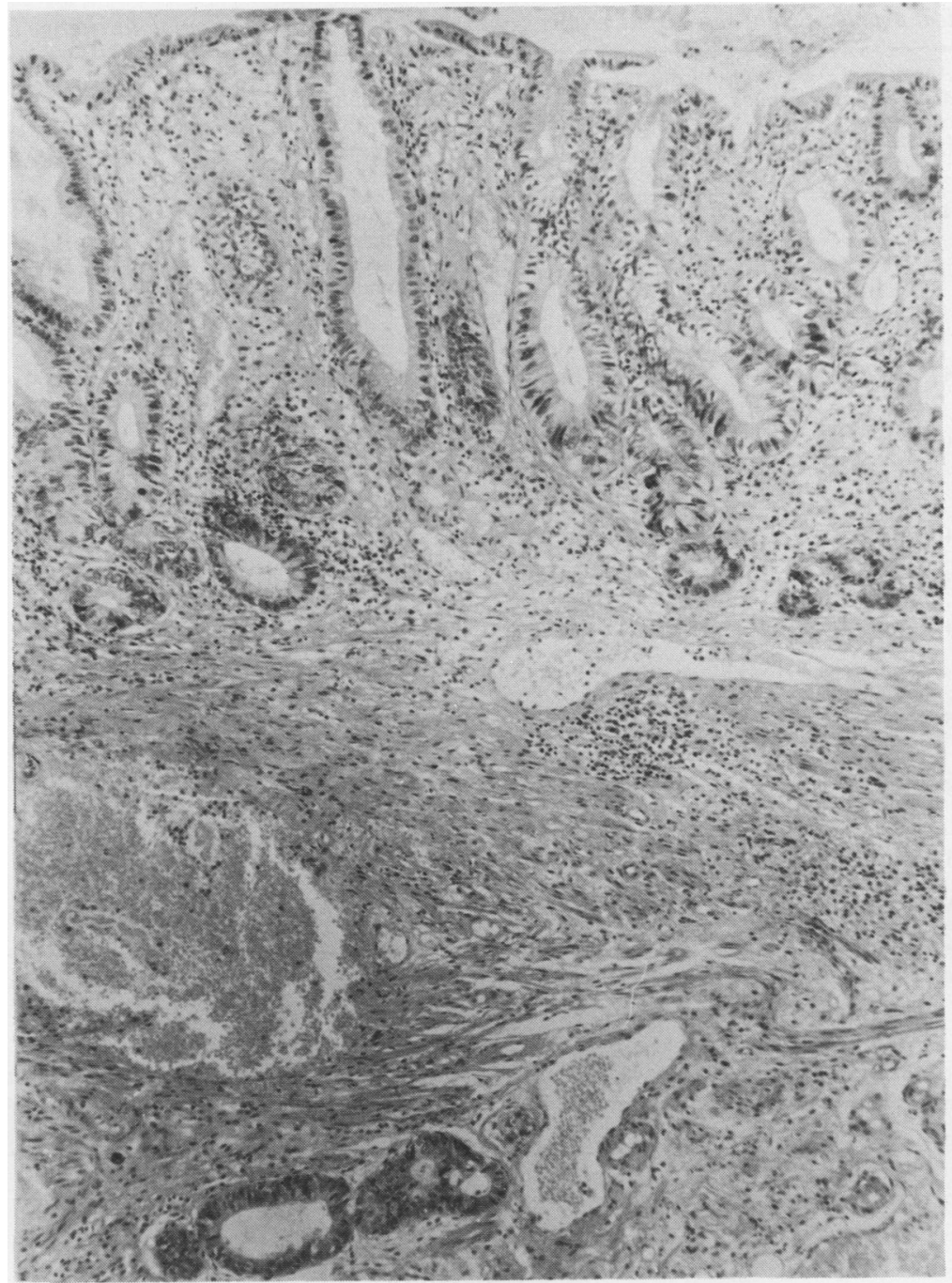

Fig. 4 Flat mucosa with attenuation in glandular architecture. The epithelium is dysplastic. There are foci of invasive carcinoma in the submucosal tissues. Haematoxylin and eosin. $\times 100$.

(Table 2), and five patients were under 50 years of age when carcinoma was diagnosed. The eight patients had a total of 14 colonic cancers, two with two tumours and two with three. Eight carcinomas were in the transverse colon, three in the ascending colon, and only two in the rectum. Four macroscopic growth patterns were recognised: (a) polypoidal carcinoma (4 cases); (b) ulcerated annular carcinoma ( 4 cases); (c) carcinoma underlying a raised mucosal plaque lesion ( 3 cases); $(d)$ carcinoma underlying a macroscopically flat mucosa ( 3 cases). The atypical growth patterns $(c)$ and $(d)$ accounted for six tumours and, interestingly, four of these were clinically unsuspected (Table 3). Three of these hidden cancers occurred in flat mucosa which showed surface histological variation from cytological dysplasia with an attenuated architecture (Fig. 4), through villous dysplasia, to frankly carcinomatous change continous with the adjacent normal mucosa. The fourth hidden "flat" cancer was a mucosal plaque lesion with villous dysplasia (Fig. 5). Two other cancers were associated with mucosal plaque lesions; both were suspected clinically, one on radiographic study and the other on colonoscopic observation (case 2 ). In case 4 the polypoid carcinoma arose in a mucosa with both villous and 
Table 1 Clinicopathological details of eight cases of ulcerative colitis complicated by carcinomatous change in the colon

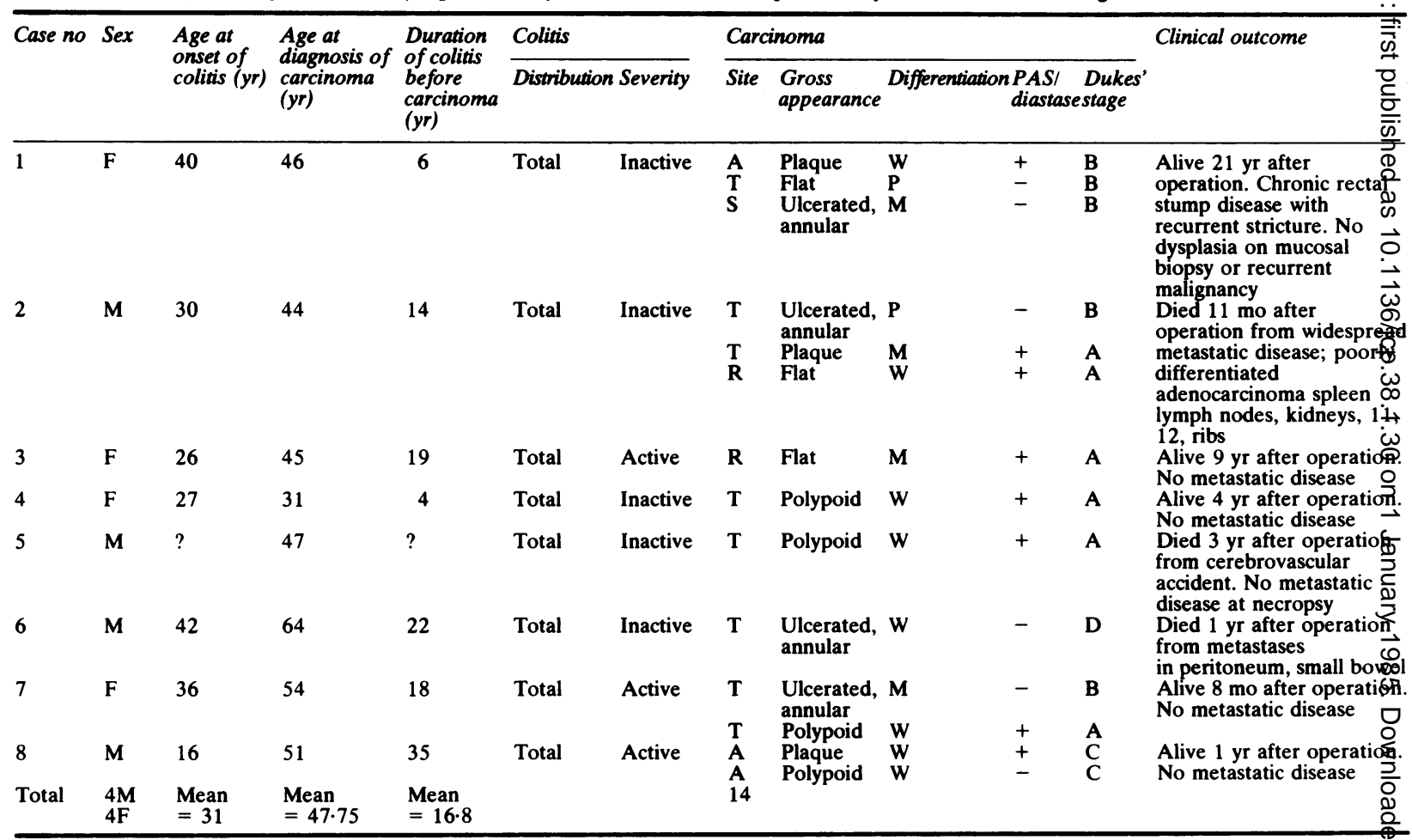

$A=$ ascending colon; $T=$ transverse colon; $D=$ descending colon; $S=$ sigmoid colon; $R=$ rectum; $W=$ well differentiated; $M=$ moderate; $P=$ poô

PAS = periodic acid Schiff.

Table 2 Summary of the age at onset of colitis and duration of the disease with relation to carcinomatous change

\begin{tabular}{lllll}
\hline Age at onset of colitis $(y r)$ & & \multicolumn{2}{l}{ Duration of colitis before proved carcinomatous change } \\
\cline { 1 - 2 } Age & Patients & & Years & Patients \\
\hline$<20$ & 1 & $<10$ & 2 \\
$20-40$ & 5 & & $10-20$ & 3 \\
$>40$ & 1 & & Mean 16.85 & 2 \\
Mean 31 & & Range 4-35 & \\
Range $16-42$ & &
\end{tabular}

Mean age at diagnosis of carcinoma $=47.75$ years.

Although there was at least a four year history in case 5, the age at onset of symptoms and duration of disease were not established. Data for case 5 are not included in the above table.

Table 3 Morphology of six clinically unsuspected carcinomas

\begin{tabular}{|c|c|c|c|c|c|}
\hline Case no & Site & Gross appearance & Differentiation & $\begin{array}{l}\text { Duke's } \\
\text { stage }\end{array}$ & Microscopy \\
\hline 1 & $\mathbf{T}$ & Flat & $\mathbf{P}$ & B & $\begin{array}{l}\text { Flat malignant mucosa continuous with adjacent normal } \\
\text { mucosa }\end{array}$ \\
\hline $\begin{array}{l}2 \\
3\end{array}$ & $\begin{array}{l}\mathbf{R} \\
\mathbf{R}\end{array}$ & $\begin{array}{l}\text { Flat } \\
\text { Flat }\end{array}$ & $\begin{array}{l}\mathbf{W} \\
\mathbf{M}\end{array}$ & $\mathbf{A}$ & $\begin{array}{l}\text { Villous mucosal dysplasia overlying carcinoma } \\
\text { Flat mucosa with attenuated architecture, but cytologically } \\
\text { dysplastic, overlying carcinoma }\end{array}$ \\
\hline 4 & $\mathbf{T}$ & Polypoid & W & $\mathbf{A}$ & $\begin{array}{l}\text { Polypoid adenocarcinoma with adjacent villous and } \\
\text { adenomatous dysplasia }\end{array}$ \\
\hline $\begin{array}{l}7 \\
8\end{array}$ & $\mathbf{T}$ & $\begin{array}{l}\text { Ulcerated annular } \\
\text { Plaque }\end{array}$ & $\begin{array}{l}\mathbf{M} \\
\mathbf{W}\end{array}$ & $\stackrel{\mathbf{B}}{\mathbf{C}}$ & $\begin{array}{l}\text { Superficially ulcerated malignant mucosa } \\
\text { Villous mucosal dysplasia overlying carcinoma }\end{array}$ \\
\hline
\end{tabular}

$\mathbf{A}=$ ascending colon; $\mathrm{T}=$ transverse colon; $\mathbf{R}=$ rectum; $\mathrm{W}=$ well differentiated; $\mathbf{M}=$ moderate; $\mathbf{P}=$ poor. 


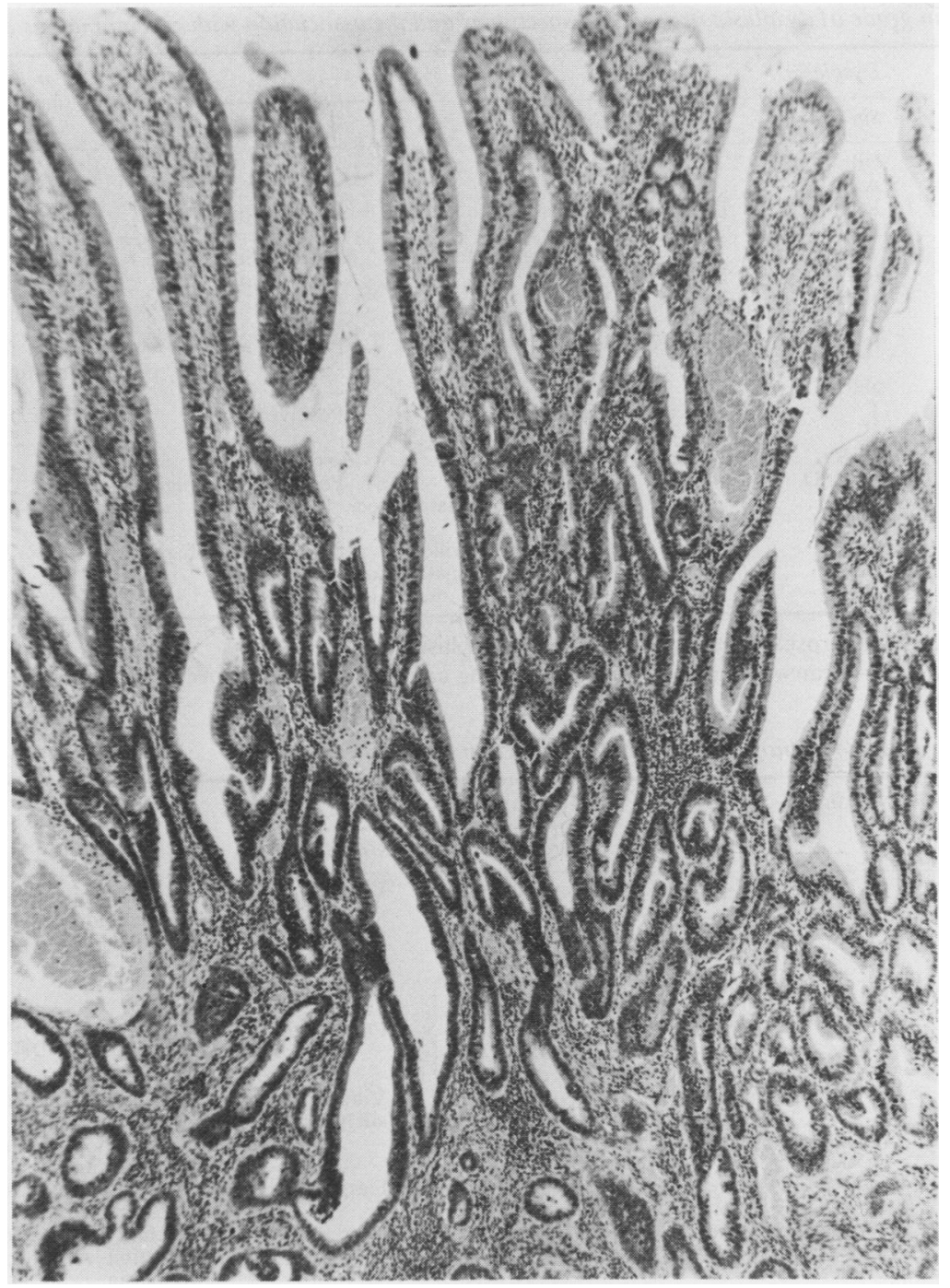

Fig. 5 Dysplastic mucosal villous fronds overlying invasive adenocarcinoma (below). This constitutes a typical mucosal plaque lesion. Haematoxylin and eosin. Original magnification $\times 70$.

polypoid adenomatous growth patterns adjacent to the tumour.

Histologically, there were eight well differentiated and four moderately differentiated adenocarcinomas. Eight of these tumours stained positively for mucin secretion. The polypoid carcinomas were well differentiated but other growth patterns showed varying grades of differentiation. Dukes' staging did not correlate with growth pattern; the flat and plaque mucosa associated tumours comprised three stage $A$, two stage $B$, and one stage C. Only three tumours had reached the stage of node involvement at the time of operation. Two of the three patients who came to necropsy did so at 11 and 12 months after operation and showed widespread metastases from their colonic adenocarcinomas. Five patients remain alive and with no clinical evidence of metastases at periods from eight months to 21 years after operation (see Table 1).

The extent and grade of mucosal dysplasia in the resection specimens are summarised in Table 4. Two patients with a total of four tumours did not show any dysplasia in the colon. Dysplasia was patchy in its colonic distribution, varying in severity from one 
Table 4 Extent and grade of dysplasia in resection specimens and the association with carcinomatous change

\begin{tabular}{|c|c|c|c|c|c|}
\hline \multirow[t]{2}{*}{ Case no } & \multicolumn{4}{|l|}{ Dysplasia } & \multirow{2}{*}{$\begin{array}{l}\text { Carcinoma associated with } \\
\text { site of dysplasia }\end{array}$} \\
\hline & Site & & Growth pattern & Grade & \\
\hline 1 & Nil & & - & - & - \\
\hline 2 & A, T, D & $\begin{array}{r}\text { Focal } \\
\text { Diffuse }\end{array}$ & Villous & Positive; low & $\mathrm{T} ; \times 2$ carcinomas \\
\hline 3 & $\hat{A}, T, D$ & Focal & $\begin{array}{l}\text { Villous, } \\
\text { adenomatous foci (3) }\end{array}$ & $\begin{array}{l}\text { Pndefinite; unknown } \rightarrow \\
\text { Positive; low }\end{array}$ & K; × 1 carcinoma \\
\hline & $\mathbf{R}$ & Diffuse & Flat & Positive; high & $\mathbf{R} ; \times 1$ carcinoma \\
\hline 4 & T, D & Focal & $\begin{array}{l}\text { Villous, } \\
\text { adenomatous foci (5) }\end{array}$ & Positive; low $\rightarrow$ high & $\mathrm{T} ; \times 1$ carcinoma \\
\hline & $\mathbf{R}$ & Diffuse & Villous & Positive; high & $\begin{array}{l}\mathbf{R} ; \times \text { focus of carcinoma } \\
\text { in situ }\end{array}$ \\
\hline $\begin{array}{l}5 \\
6\end{array}$ & Nil & & $\overline{F l a t}$ & $\bar{P}$ itive & $\bar{T}$ \\
\hline 6 & $\mathbf{T}$ & Focal & $\begin{array}{l}\text { Flat, } \\
\text { adenomatous foci (2) }\end{array}$ & Positive; low & $1 ; \times 1$ carcinoma \\
\hline 7 & $\begin{array}{l}\text { D, R } \\
\text { A, T, D }\end{array}$ & $\begin{array}{r}\text { Not resected } \\
\text { Focal }\end{array}$ & $\begin{array}{l}\text { Villous } \\
\text { multiple adenomatous foci }\end{array}$ & Positive; low $\rightarrow$ high & $\mathrm{T} ; \times 2$ carcinomas \\
\hline 8 & $\begin{array}{l}\text { R } \\
\text { A, T } \\
\text { D, R }\end{array}$ & $\begin{array}{r}\text { Focal } \\
\text { Diffuse } \\
\text { (nil) }\end{array}$ & $\begin{array}{l}\text { Predominantly villous } \\
\text { (flat and adenomatous foci } \\
\text { also seen) }\end{array}$ & Positive; low $\rightarrow$ high & A; $\times 2$ carcinomas \\
\hline
\end{tabular}

Four tumours in two cases arose in mucosa negative for dysplasia.

$\mathrm{A}=$ ascending colon; $\mathrm{T}=$ transverse colon; $\mathrm{D}=$ descending colon; $\mathrm{R}=$ rectum.

Table 5 Pathology of mucosal biopsies taken before resection for carcinoma

\begin{tabular}{|c|c|c|c|c|c|c|}
\hline \multirow[t]{2}{*}{ Case no } & \multirow{2}{*}{$\begin{array}{l}\text { No of months } \\
\text { before resection }\end{array}$} & \multirow[t]{2}{*}{ Site } & \multirow{2}{*}{$\begin{array}{l}\text { Severity of } \\
\text { inflammation }\end{array}$} & \multicolumn{2}{|l|}{ Dysplasia } & \multirow[t]{2}{*}{ Comments } \\
\hline & & & & Grade & Growth pattern & \\
\hline \multirow[t]{4}{*}{2} & 12 & $\mathbf{R}$ & Inactive & Positive; low & Villous & \multirow[t]{3}{*}{$\begin{array}{l}\text { Suspect gross appearance noted } \\
\text { on sigmoidoscopy }\end{array}$} \\
\hline & 12 & $\mathbf{R}$ & Inactive & Positive; high & \multirow[t]{2}{*}{$\begin{array}{l}\text { Villous, } \\
\text { adenomatous }\end{array}$} & \\
\hline & 5 & A & Inactive & $\begin{array}{l}\text { Indefinite; } \\
\text { unknown }\end{array}$ & & \\
\hline & 5 & $\mathbf{T}$ & Inactive & $\begin{array}{l}\text { unknown } \\
\text { Indefinite; } \\
\text { negative }\end{array}$ & Flat mucosa & $\begin{array}{l}\text { Resection specimen focally positive } \\
\text { for low grade dysplasia }\end{array}$ \\
\hline 4 & $\begin{array}{l}5 \\
1\end{array}$ & $\begin{array}{l}\mathbf{D} \\
\mathbf{R}\end{array}$ & $\begin{array}{l}\text { Active } \\
\text { Inactive }\end{array}$ & $\begin{array}{l}\text { Negative } \\
\text { Positive; low }\end{array}$ & \multirow{2}{*}{$\begin{array}{l}\text { Villous, } \\
\text { adenomatous } \\
\text { _ }\end{array}$} & \multirow{6}{*}{$\begin{array}{l}\text { Suspect gross appearance. Positive high } \\
\text { grade in resection. } \\
\text { Rectum not subsequently resected or } \\
\text { biopsied further } \\
\text { Rectum focally positive for dysplasia } \\
\text { in resection } \\
\text { Rectum negative for dysplasia in } \\
\text { resection. A, T high grade villous } \\
\text { dysplasia } \\
\text { *Except biopsy no } 5 \text { at } 50 \mathrm{~cm} \text { from } \\
\text { ileocaecal valve indefinite dysplasia; } \\
\text { unknown }\end{array}$} \\
\hline 6 & 2 & $\mathbf{R}$ & Inactive & Negative & & \\
\hline 7 & 1 & $\mathbf{R}$ & Active & Negative & Flat mucosa & \\
\hline \multirow[t]{3}{*}{8} & 10 & $\mathbf{R}$ & Active & Negative & - & \\
\hline & \multirow[t]{2}{*}{9} & $\begin{array}{l}\text { Colon } \\
\times 14\end{array}$ & Inactive & Negative $^{*}$ & \multirow[t]{2}{*}{ - } & \\
\hline & & $\begin{array}{l}17 C \\
6 R\end{array}$ & & $\begin{array}{c}14 \text { negative } C \\
3 \text { indefinite } C \\
3 \text { negative } R \\
3 \text { positive } R\end{array}$ & & \\
\hline
\end{tabular}

$A=$ ascending colon: $T=$ transverse colon: $D=$ descending colon: $R=$ rectum: $C=$ colonic:

part of the colon to another and sometimes focal within individual glands (Fig. 7). The transverse and left colon and rectum were more consistently affected and often to a higher grade than the right colon. Rectal dysplasia was generally more diffuse and of a high grade, and in all four cases associated with at least focal low grade dysplasia elsewhere in the colon. In one case there was dysplastic colonic mucosa with normal rectal mucosa. Three of the four cases with rectal dysplasia harboured two carcinomas and an area of carcinoma in situ within the rectum. The fourth had two tumours in the transverse colon. When dysplasia was present it was found both adjacent to and away from the tumour Five cancers arose in areas of low grade dysplasia and five in high grade dysplasia. The grade of dys- 


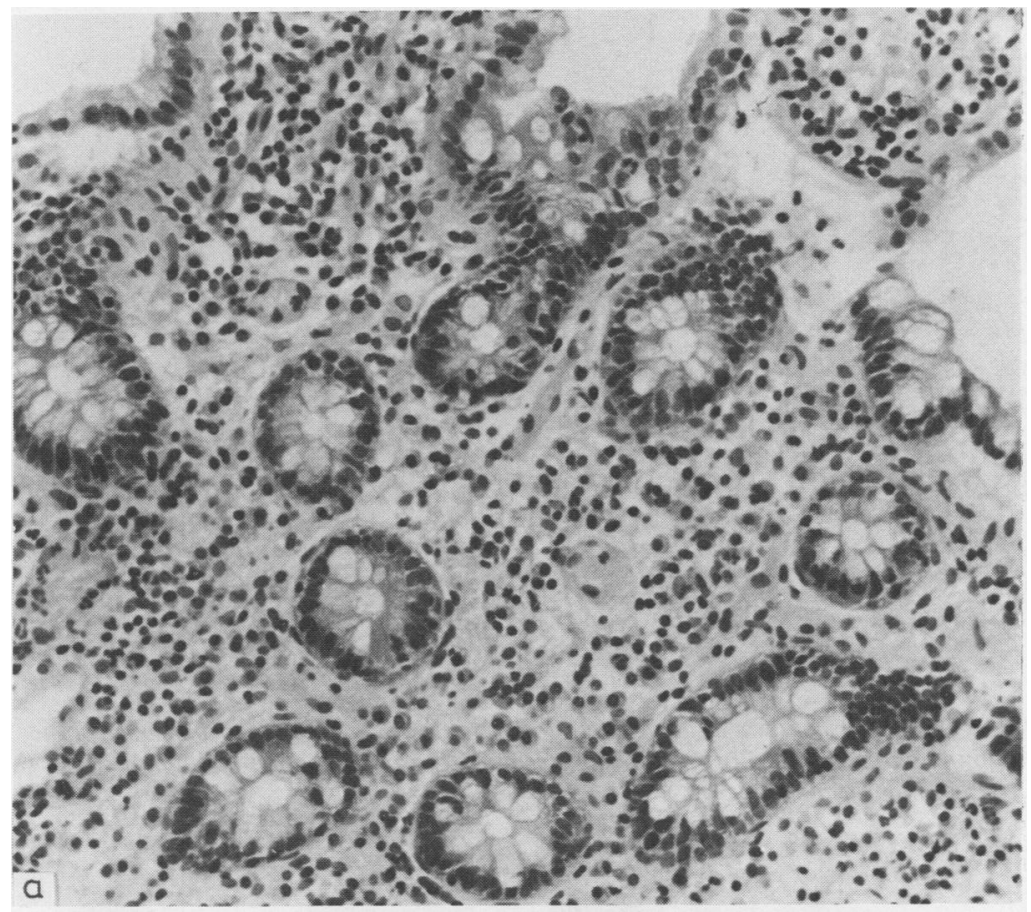

Fig. 6(a) Case 8. A representative mucosal colonic biopsy showing quiescent colitis. Negative for dysplasia. Haematoxylin and eosin. Original magnification $\times$ 250. (b) Colonic biopsy no 5 from case 8 ( $50 \mathrm{~cm}$ from the ileocaecal valve). Numerous dystrophic goblet cells are present. There is nuclear pleomorphism and a tendency for nuclear stratification. Indefinite for dysplasia: unknown. Haematoxylin and eosin. Original magnification $\times 240$.

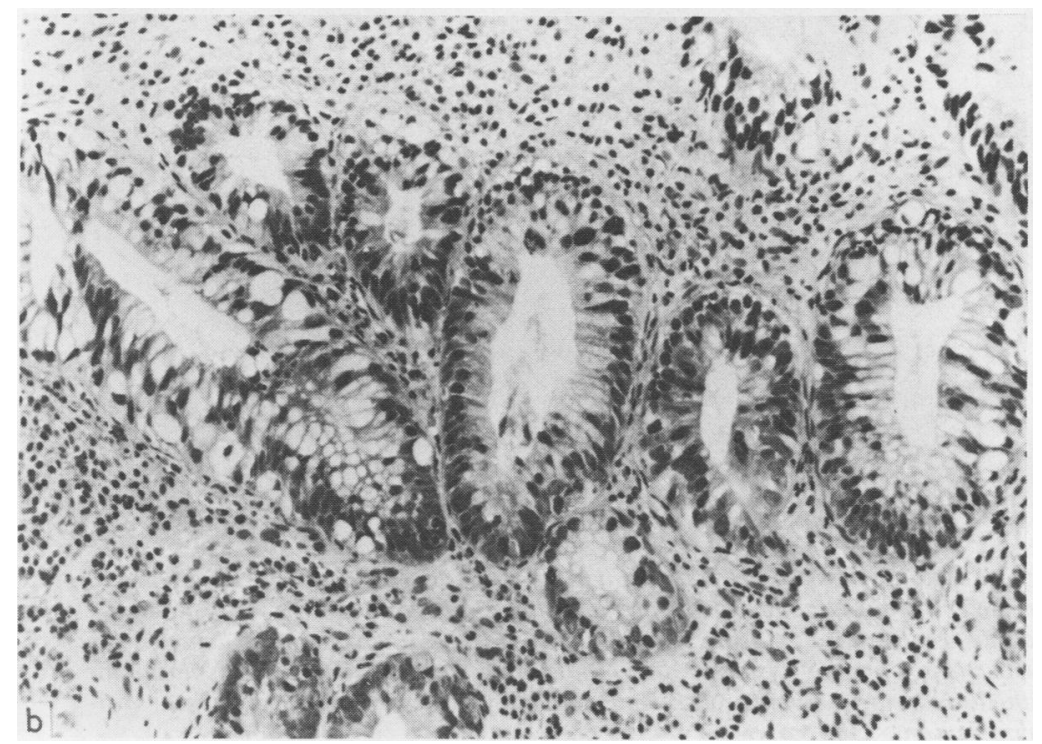




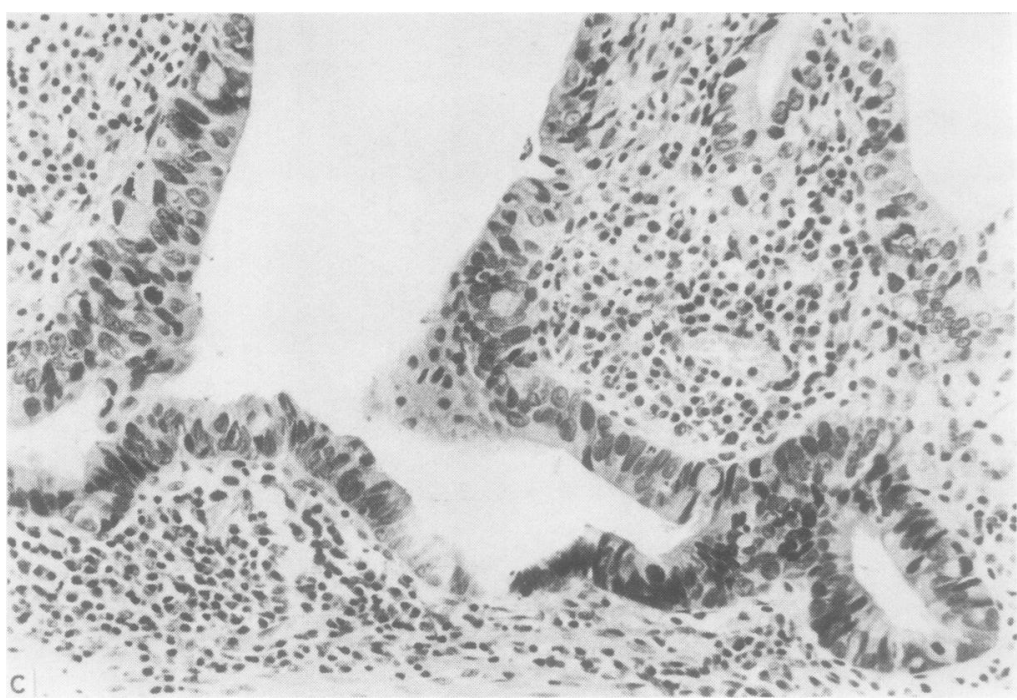

Fig. 6(c) Representation of the mucosa found in the ascending and transverse colon only nine months later. Positive for dysplasia: high grade. Haematoxylin and eosin. Original magnification $\times 300$.

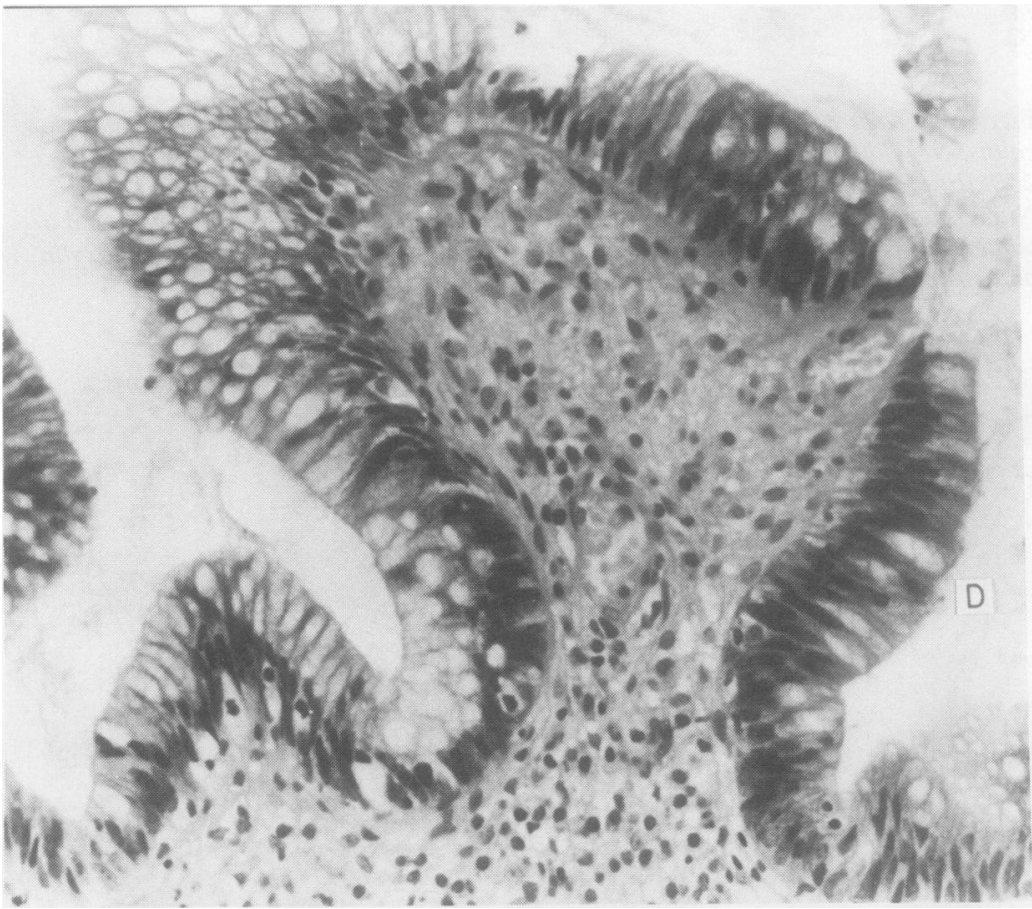

Fig. 7 Colonic mucosa with quiescent inflammation. There is a villous architecture and the epithelium on the right of the field shows nuclear hyperchromatism and stratification confined to the basal half of the cell (D). Mucin content is depleted. This mucosa is positive for dysplasia: low grade. Note the focal nature of dysplasia, the epithelium on the left being negative. Haematoxylin and eosin. Original magnification $\times 380$. 
plasia did not influence the number of tumours in each bowel or their differentiation or staging. Eight tumours were associated with villous mucosal dysplasia and two with flat mucosal dysplasia. The next most common dysplastic mucosal growth pattern to that of villous fronds was polypoidal adenomatous proliferation. Three of the four resections with polypoid carcinomas also contained multiple adenomatous foci in the mucosa.

The pathological findings in the mucosal biopsies taken before resection are detailed in Table 5. There was a total of 23 biopsies ( 6 rectal, 17 colonic) taken from five patients, all less than 12 months before resection for carcinoma. In two the polypoid configuration had raised clinical suspicion at sigmoidoscopy. These and a third rectal biopsy were positive for dysplasia. The resection specimens confirmed dysplasia with a carcinoma and carcinoma in situ in the rectums. The respective transverse colons had also undergone carcinomatous change. Two rectal biopsies negative for dysplasia showed focal rectal dysplasia and no rectal dysplasia at resection. Both bowels contained colonic dysplasia and carcinoma (cases 7 and 8). Colonic biopsy was performed in only two patients. Three biopsies were graded indefinite for dysplasia, the resection specimens showing patchy positivity. Of the 14 colonic biopsies negative for dysplasia, 10 showed positive dysplasia at roughly equivalent anatomical sites in the resection specimens. Comment was made at colonoscopy in case 2 regarding a suspicious macroscopic lesion in the transverse colon. The biopsy was graded indefinite for dysplasia but the resection specimen showed carcinoma with mucosal villous dysplasia. All colonic biopsies were taken within five and nine months of resection, including a total of 14 from one patient (case 8, Fig. 6).

\section{Discussion}

Mucosal dysplasia and carcinoma have undoubtedly become established as uncommon but important complications in both ulcerative colitis and Crohn's disease. ${ }^{24} 25$ A recently published paper on the morphology of colitic dysplasia has laid down well illustrated and considered guidelines. ${ }^{22}$ The institution of such an internationally agreed classification will serve as a basis for those of us working in general histopathology laboratories by which we may assess the risk of malignancy developing in colitic mucosa. Two questions must be asked: is this mucosa dysplastic, and, if so, of what importance is it to the patient?

In an attempt to answer these problems the international classification may be applied in two ways. Firstly, mucosal and tumour morphology may be documented in bowels resected either for nonresponsive chronic disease or because of carcinomatous change. This should lead to a better understanding of both the recognition and distribution of mucosal dysplasia and the parameters by which early carcinomatous change may be detected. Secondly, with the advent of more widespread colonoscopy facilities, there exists the opportunity not only to visualise early malignant mucosal lesions but also to biopsy colitic mucosa. ${ }^{14} 15171821$ This is important so that the natural history of dysplasia in ulcerative colitis may be determined in much the same way as has been done for premalignant lesions in other sites - for example, the uterine cervix. ${ }^{26}$

Our series illustrates a number of points concerning malignant mucosal changes in ulcerative colitis. Half of the patients had more than one primary colonic tumour and the distribution was more even throughout the bowel, ${ }^{10}$ with emphasis on the ascending and transverse colon rather than the rectosigmoid region. Most tumours were well or moderately differentiated with a high proportion secreting mucin. ${ }^{10}$ Only three cancers had advanced to lymph node involvement at the time of operation. Two patients died from metastatic disease within one year but five remain alive and well, three of them more than four years after operation. Prognosis is therefore variable. Assessing pathological features such as the grade of mucosal dysplasia in the resection, the degree of tumour differentiation, and mucin secretion were not reliable indicators of subsequent biological behaviour. In the light of such an unpredictable outlook the morphology of both malignant and premalignant colonic changes must be recognised as an aid to early diagnosis and hence better prognosis.

Atypical tumour growth patterns and the potential for occult cancer in ulcerative colitis have been documented by Cook and Goligher. ${ }^{10}$ In their series, 18 of 26 carcinomas were unusual in resembling fibrous strictures, flat plaques, or in being macroscopically unrecognisable (five tumours). Six of our 14 cancers showed the unusual patterns of mucosal plaque lesions and flat mucosa. Only two of these were diagnosed clinically, and this diagnostic pitfall emphasises earlier comments on the inefficiency of relying on radiological assessment alone. ${ }^{27}$ Six of our cancers were undiagnosed at the time of resection, one occurring in a mucosal plaque lesion and three in macroscopically flat mucosa which showed varied histological features. Two consequences arise from this. Firstly, colonoscopy can reveal gross mucosal lesions which, if biopsied, will give a high yield of dysplasia or carcinoma. Plaque lesions and polypoidal mucosa have been found particularly fruitful. ${ }^{151718}$ Secondly, carcinoma may be covered by 
grossly normal or flat, dysplastic mucosa. ${ }^{7}$ Several studies have therefore recommended biopsy of both suspicious lesions and, at intervals, the rest of the mucosa, ${ }^{182224}$ perhaps every $10 \mathrm{~cm}$. A fifth occult cancer in our series arose from polypoid adenomatous foci. Finding such a mucosal configuration is undoubtedly important in the evolution of cancer, particularly in a colitic patient younger than the more usual adenoma bearing age. Because the occurrence of mucosal adenomas is also common in non-colitic patients, confirmation of significant dysplasia should be sought in the mucosa adjacent to such a polyp..$^{22}$ The colonoscopic identification of true adenomatous lesions may prove difficult in mucosa with inflammatory pseudopolypi.

Mucosal dysplasia in this series was patchy in distribution, varied in severity throughout the colon, and was sometimes focal within glands. It was present in mucosa adjacent to and away from tumours. The predominant growth patterns were villous mucosal fronds, adenomatous polypoid foci, and flat dysplastic mucosa." 24 The left colon and rectum were more severely affected both in distribution and grade. " A negative rectal mucosa, both on biopsy and in a resection specimen, did not exclude the possibility of dysplasia or tumour in the rest of the colon (case 8)..$^{10}$ Focal rectal dysplasia also led to a false negative rectal mucosal biopsy (case 7)..$^{11} 2428$ Rectal mucosa positive for dysplasia implied dysplastic or carcinomatous changes either in the rectum or elsewhere in the colon at resection. ${ }^{716}$ Colonoscopic biopsy in case 2 confirmed the possibility of false negative biopsy due to the patchy distribution of dysplasia. ${ }^{29}$ Colonoscopic surveillance in case 8 proved particularly disturbing. Nine months before resection mucosal biopsy over the length of the colon showed 13 biopsies negative for dysplasia and one biopsy indefinite for dysplasia. The resection contained two carcinomas in the ascending colon and diffuse high grade dysplasia in the ascending and transverse colon (Fig. 6). This suggests that rarely colitic dysplasia may be rapidly progressive. Case 4 , showing both dysplasia and carcinoma, had a clinical history of only four years. Carcinoma in ulcerative colitis of less than 10 years' duration is unusual but has been noted previously. Kewenter described one case with a six year history, ${ }^{16}$ and Cook and Goligher noted three cases with disease durations of three, six, and nine years. ${ }^{10}$ This should alert clinicians to the possibility of dysplasia and carcinoma in ulcerative colitis occurring either at an early stage in the disease or pursuing an unusually rapid course. This aggressive outcome contrasts with Riddell's proposed model of the onset of dysplasia at 14 years disease duration, with early invasion and clinical tumour detection at 15 and 18 years, respec- tively. ${ }^{11}$

These differing possibilities should be borne in mind in patient management. We suggest that, even early in the disease course, an uncharacteristic exacerbation of symptoms should be regarded with suspicion. This applies particularly in a patient who develops a stricture on $x$ ray contrast examination ${ }^{27}$ or an endoscopically suspect gross lesion. ${ }^{17} \mathrm{We}$ also think that a negative surveillance colonic biopsy should not lead to undue relaxation in subsequent follow up procedures. This caution is warranted owing to the patchy nature of colitic dysplasia and the unusual possibility of dysplasia pursuing an aggressively rapid course. The reader is referred elsewhere for discussion on the management of colitic patients regarding surveillance endoscopy. ${ }^{131822}$ General recommendations are that patients with total colitis of 10 years' or more duration should be investigated annually, and colonoscopy rather than radiology is now the method of choice. Biopsies should be taken from suspicious gross lesions and flat mucosa.

The pathologist should be acquainted with the range of epithelial lesions seen in regenerative activity and dysplasia so that mucosa of indefinite or low grade dysplasia may be further assessed by short term review biopsy. A second more crucial distinction must be made with reference to high grade mucosal dysplasia as this is justification for colectomy. By use of the international classification and discussion with clinicians and fellow pathologists, we hope that in the future we may document more accurately the relevance of various mucosal changes in ulcerative colitis and their therapeutic implications for the patient.

We gratefully acknowledge the following surgeons for their kind permission to publish details concerning their patients: Mr WA Hanna, Mr RC Curry, Mr TEB Dane, Mr DG Mudd, Mr JDA Robb, Mr JT Ward, and Mr SA Zaheer. We thank Mr J Orchin and his staff for preparing the histological sections and Mrs Jill Lockhart for typing the manuscript.

\section{References}

' Crohn BB, Rosenberg H. The sigmoidoscopic picture of chronic ulcerative colitis (non-specific). Am J Med Sci 1925; 170: $220-8$.

2 Bargen JA. Chronic ulcerative colitis associated with malignant disease. Arch Surg 1928;17:561-76.

${ }^{3}$ Svartz N, Ernberg T. Cancer coli in cases of colitis ulcerosa. Acta Med Scand 1949; 135:444-7.

${ }^{4}$ Warren S, Sommers SC. Pathogenesis of ulcerative colitis. Am J Pathol 1949;25:657-79.

s Dawson IMP, Pryse-Davies J. The development of carcinoma of the large intestine in ulcerative colitis. $B r J$ Surg 1959;47:113-28.

${ }^{\circ}$ Edwards FC, Truelove SC. The course and prognosis of ulcera- 
tive colitis. Gut 1964;5: 15-22.

${ }^{7}$ Morson BC, Pang LSC. Rectal biopsy as an aid to cancer control in ulcerative colitis. Gut 1967;8:423-34.

${ }^{8}$ Evans DJ, Pollock DJ. In-situ and invasive carcinoma of the colon in patients with ulcerative colitis. Gut 1972;13:566-70.

" Yardley JH, Keren DF. "Precancer' lesions in ulcerative colitis: a retrospective study of rectal biopsy and colectomy specimens. Cancer 1974;34:835-44.

${ }^{10}$ Cook MG, Goligher JC. Carcinoma and epithelial dysplasia complicating ulcerative colitis. Gastroenterology 1975; 68: $1127-36$.

" Riddell RH. The precarcinomatous phase of ulcerative colitis. In: Morson BC, ed. Current topics in pathology of the gastrointestinal tract. Berlin: Springer, 1976:179-219.

12 Lennard-Jones JE, Morson BC, Ritchie JK, Shove DC, Williams CB. Cancer in colitis: assessment of the individual risk by clinical and histological criteria. Gastroenterology 1977;73:12809.

${ }^{13}$ Butt JH, Lennard-Jones JE, Ritchie JK. A practical approach to the risk of cancer in inflammatory bowel disease. Med Clin North Am 1980;64: 1203-20.

${ }^{14}$ Granqvist S, Gabrielsson N, Sundelin P, Thorgeirsson T. Precancerous lesions in the mucosa in ulcerative colitis: a radiographic, endoscopic and histopathologic study. Scand J Gastroenterol 1980; 15:289-96.

is Blackstone MO, Riddell RH, Rogers BHG, Levin B. Dysplasia-associated lesion or mass (DALM) detected by colonoscopy in long-standing ulcerative colitis: an indication for colectomy. Gastroenterology 1981;80:336-74.

${ }^{10}$ Kewenter J, Hulten L, Ahren C. The occurrence of severe epithelial dysplasia and its bearing on treatment of longstanding ulcerative colitis. Ann Surg 1982; 195:209-13.

${ }^{17}$ Butt JH, Konishi F, Morson BC, Lennard-Jones JE, Ritchie JK. Macroscopic lesions in dysplasia and carcinoma complicating ulcerative colitis. Dig Dis Sci 1983;28:18-26.

${ }^{18}$ Lennard-Jones JE, Morson BC, Ritchie JK, Williams CB. Cancer surveillance in ulcerative colitis: experience over 15 years. Lancet $1983 ;$ i: $149-52$.

14 Devroede G, Taylor WF. On calculating cancer risk and survival of ulcerative colitis patients with the life table method. Gastroenterology 1976; 71:505-9.

${ }^{20}$ Fuson JA, Farmer RG, Hawk WA, Sullivan BH. Endoscopic surveillance for cancer in chronic ulcerative colitis. Am J Gastroenterol 1980;73:120-6.

2 Dickinson RJ, Dixon MF, Axon ATR. Colonoscopy and the detection of dysplasia in patients with longstanding ulcerative colitis. Lancet 1980;ii:620-2.

2: Riddell RH, Goldman H, Ransohoff DF, et al. Dysplasia in inflammatory bowel disease: standardised classification with provisional clinical applications. Hum Pathol 1983; 14:931-68.

${ }^{23}$ Dukes CE, Bussey HJR. The spread of rectal cancer and its effect on prognosis. Br J Cancer 1958; 12:309-20.

${ }^{24}$ Riddell RH. Dysplasia in inflammatory bowel disease. Clin Gastroenterol 1980;9:439-58.

${ }^{25}$ Simpson S, Traube J, Riddell RH. The histological appearance of dysplasia (precarcinomatous change) in Crohn's disease of the small and large intestine. Gastroenterology 1981;81:492.

${ }^{26}$ Richart RM, Barron BB. A follow-up study of patients with cervical dysplasia. Am J Obstet Gynaecol 1969; 105:386.

${ }^{27}$ Fennessy JJ, Sparberg MB, Kirsner JB. Radiologic findings in carcinoma of the colon complicating ulcerative colitis. Gut 1968;9:388-97.

${ }^{28}$ Riddell RH, Morson BC. Value of sigmoidoscopy and biopsy in detection of carcinoma and premalignant change in ulcerative colitis. Gut 1979;20:575-80.

${ }^{24}$ Crawson TD, Ferrante WF, Gathright JB Jr. Colonoscopy: inefficacy for early carcinoma detection in patients with ulcerative colitis. JAMA 1976;236:2651-2.

Requests for reprints to: Dr Derek Allen, Histopathology Laboratory, Belfast City Hospital, Lisburn Road, Belfast BT9 7AD, Northern Ireland. 